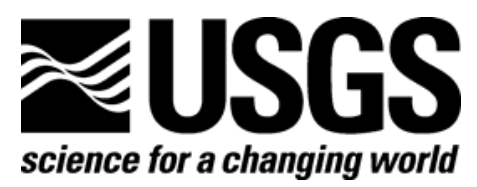

In cooperation with the City of Austin

\title{
Concentrations of Polycyclic Aromatic Hydrocarbons (PAHs) and Major and Trace Elements in Simulated Rainfall Runoff From Parking Lots, Austin, Texas, 2003
}

By Barbara J. Mahler, Peter C. Van Metre, and Jennifer T. Wilson

Open-File Report 2004-1208, version 3 


\section{U.S. Department of the Interior DIRK KEMPTHORNE, Secretary}

\section{U.S. Geological Survey \\ Mark D. Myers, Director}

U.S. Geological Survey, Reston, Virginia: 2004

Revised and reprinted: 2007

For product and ordering information:

World Wide Web: http://www.usgs.gov/pubprod

Telephone: 1-888-ASK-USGS

For more information on the USGS - the Federal source for science about the Earth,

its natural and living resources, natural hazards, and the environment:

World Wide Web: http://www.usgs.gov

Telephone: 1-888-ASK-USGS

Suggested citation:

Mahler, B.J., Van Metre, P.C., and Wilson, J.T., 2004 [revised 2007], Concentrations of polycyclic aromatic hydrocarbons (PAHs) and major and trace elements in simulated rainfall runoff from parking lots, Austin, Texas, 2003 (version 3): U.S. Geological Survey Open-File Report 2004-1208, 87 p. [Online only].

Any use of trade, product, or firm names is for descriptive purposes only and does not imply endorsement by the U.S. Government.

Although this report is in the public domain, permission must be secured from the individual copyright owners to reproduce any copyrighted material contained within this report. 


\section{Contents}

Abstract

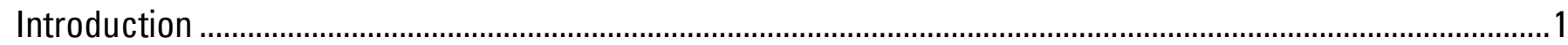

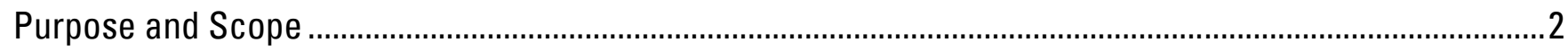

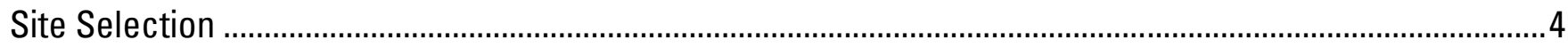

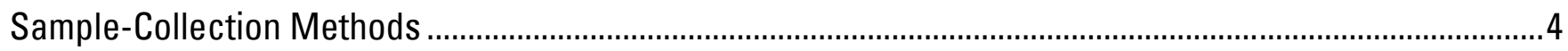

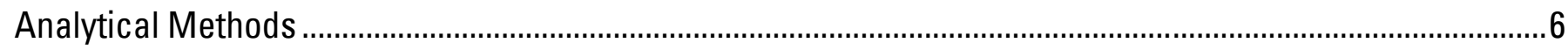

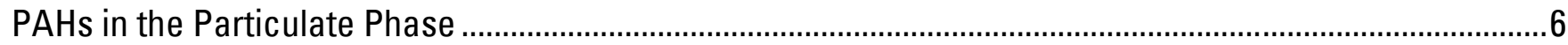

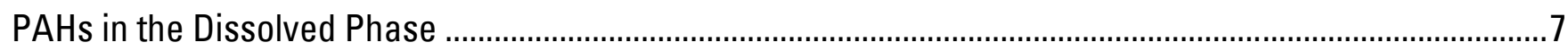

Major and Trace Elements in the Particulate Phase ………........................................................................ 8

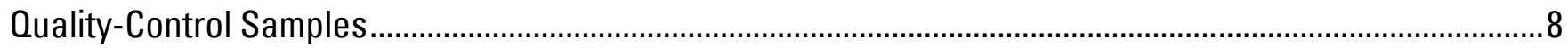

PAHs and Major and Trace Elements in Simulated Rainfall Runoff..............................................................

PAHs

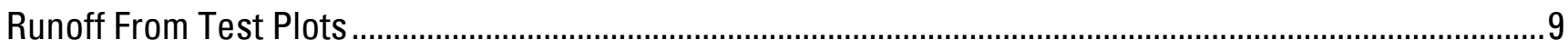

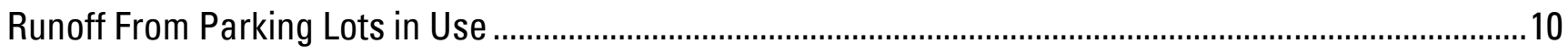

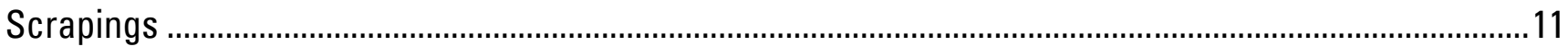

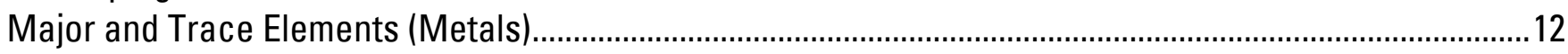

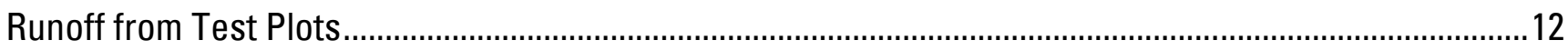

Runoff from Parking Lots in Use ................................................................................................... 12

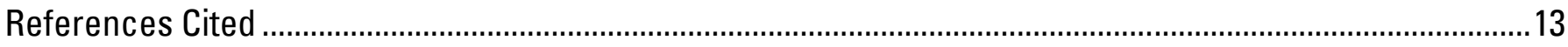

\section{Figures}

1. Map showing location of parking lots for sampling of simulated runoff, Austin, Texas, 2003

2-7. Graphs showing:

2. Rainfall for the sampling period as recorded at the National Weather Service Austin Camp Mabry station and dates washoff samples collected

3. Concentrations of total particulate polycyclic aromatic hydrocarbons ( $\left.\Sigma P A H_{\text {part }}\right)$ in washoff samples from four test plots in Austin, Texas, 2003

4. Concentrations of total dissolved polycyclic aromatic hydrocarbons ( $\Sigma P A H_{\text {diss}}$ ) in washoff samples from four test plots in Austin, Texas, 2003

5. Concentrations of total particulate polycyclic aromatic hydrocarbons ( $\Sigma \mathrm{PAH} \mathrm{H}_{\text {part }}$ in washoff samples from test plots and parking lots in use, Austin, Texas, 2003

6. Concentrations of total dissolved polycyclic aromatic hydrocarbons ( $\Sigma P A H_{\text {diss }}$ ) in washoff samples from test plots and parking lots in use, Austin, Texas, 2003

7. Concentrations of total particulate polycyclic aromatic hydrocarbons ( $\left.\Sigma P A H_{\text {part }}\right)$ in scrapings samples from test plot and parking lot surfaces in Austin, Texas, 2003

\section{Tables}

1. Selected characteristics of sites for sampling simulated rainfall runoff from parking lots, Austin, 
2. Particulate-phase concentrations of polycyclic aromatic hydrocarbons in washoff and scrapings samples from parking lots, Austin, Texas, 2003.

3. Dissolved-phase concentrations of polycyclic aromatic hydrocarbons in washoff samples from parking lots, Austin, Texas, 2003

4. Particulate-phase concentrations of major and trace elements in washoff samples from parking lots, Austin, Texas, 2003 .80

5. Suspended sediment concentrations in washoff samples from parking lots, Austin, Texas, 2003 .86 


\title{
Concentrations of Polycyclic Aromatic Hydrocarbons (PAHs) and Major and Trace Elements in Simulated Rainfall Runoff From Parking Lots, Austin, Texas, 2003
}

\author{
By Barbara J. Mahler, Peter C. Van Metre, and Jennifer T. Wilson
}

\section{Abstract}

Samples of creek bed sediment collected near seal-coated parking lots in Austin, Texas, by the City of Austin during 2001-02 had unusually elevated concentrations of polycyclic aromatic hydrocarbons (PAHs). To investigate the possibility that PAHs from seal-coated parking lots might be transported to urban creeks, the U.S. Geological Survey, in cooperation with the City of Austin, sampled runoff and scrapings from four test plots and 13 urban parking lots. The surfaces sampled comprise coal-tar-emulsionsealed, asphalt-emulsion-sealed, unsealed asphalt, and unsealed concrete. Particulates and filtered water in runoff and surface scrapings were analyzed for PAHs. In addition, particulates in runoff were analyzed for major and trace elements. Samples of all three media from coal-tar-sealed parking lots had concentrations of PAHs higher than those from any other types of surface. The mean total PAH concentration in particulates in runoff from parking lots in use were 3,500,000, 620,000, and 54,000 micrograms per kilogram from coal-tar-sealed, asphalt-sealed, and unsealed (asphalt and concrete combined) lots, respectively. The probable effect concentration sediment quality guideline is 22,800 micrograms per kilogram. The mean total PAH (sum of detected PAHs) concentration in filtered water from parking lots in use was 8.6 micrograms per liter for coal-tar-sealed lots; the one sample analyzed from an asphalt-sealed lot had a concentration of 5.1 micrograms per liter and the one sample analyzed from an unsealed asphalt lot was 0.24 microgram per liter. The mean total PAH concentration in scrapings was 23,000,000, 820,000, and 14,000 micrograms per kilogram from coal-tar-sealed, asphalt-sealed, and unsealed asphalt lots, respectively. Concentrations of lead and zinc in particulates in runoff frequently exceeded the probable effect concentrations, but trace element concentrations showed no consistent variation with parking lot surface type.

\section{Introduction}

Contamination of aquatic sediments by polycyclic aromatic hydrocarbons (PAHs), which represent the largest class of suspected carcinogens (Björseth and Ramdahl, 1985), has been increasing over the last 20 to 40 years (Van Metre and others, 2000). PAHs in the environment largely are a product of the incomplete combustion of petroleum, oil, coal, and wood (Edwards, 1983). Suspected sources in the urban environment include vehicles, home heating with wood and coal, and power plants (Sims and Overcash, 1983). 
During 2001-02, samples of creek bed sediment collected near seal-coated parking lots in Austin, Tex., by the City of Austin had unexpectedly high levels of PAHs (City of Austin, 2005). In 2003, sediment collected by the City of Austin from several parking lot surfaces in Austin had PAH concentrations that exceeded sediment quality guidelines for health of benthic aquatic organisms (MacDonald and others, 2000) by more than two orders of magnitude, prompting city staff to theorize that the sealers coating the parking lots could be the cause (City of Austin, 2005).

In the United States, sealers are applied to parking lots and driveways to enhance appearance and to protect the underlying asphalt pavement. The most commonly used sealers have a coal-tar-emulsion base, although asphalt-emulsion-based sealers also are available. Many companies recommend reapplication every 2 to 3 years (Carolina Asphalt, Inc., 2006; Colorado Asphalt Services, Inc., 2006; Riegler Blacktop, Inc., 2006; Asphalt Sealcoat Manufacturers Association, 2007). City of Austin staff estimate that about 660,000 gallons (2,500 cubic meters) of coal-tar-emulsion-based sealers are used annually in Austin (City of Austin, 2005). Although figures on national use are not available, The Blue Book of Building and Construction, a directory for the construction industry (Contractors Register, Inc., 2004), lists more than 3,500 pavement sealer companies in 30 states. As an example of sealer use, one commercial sealer applicator, New England Sealcoating, estimates that it has sealed more than 325,000,000 square feet (about 30 square kilometers) of pavement (New England Sealcoating, 2003).

Although coal-tar-emulsion-based and asphalt-emulsion-based sealers are both shiny black, they are produced through different processes and have different molecular structures. Coal tar is derived from the destructive distillation of coal to produce coke and gas. Coal tar is 50-percent or more PAHs by weight (U.S. Department of Health and Human Services, 2002), and coal-tar-emulsion-based sealers typically are 20- to 35-percent refined coal tar by weight (for example, STAR, Inc., 1996; Neyra Industries, 2000; SealMaster, 2002). Coal tar is a known human carcinogen, and wastes containing coal tar are subject to reporting under the U.S. Environmental Protection Agency's hazardous waste disposal rule (U.S.

Department of Health and Human Services, 2002). In contrast, asphalt is derived from the refining of crude petroleum and contains concentrations of PAHs that are several orders of magnitude less than those in coal tar (Takada and others, 1990). Analyses of commercially available coal-tar-emulsion-based sealers indicated concentrations of total PAH (sum of 16 parent PAHs) ranging from 5 to 600 times greater than those in asphalt-emulsion-based sealers (City of Austin, 2005).

Data collected by the City of Austin indicate that parking lot sealers contain extremely high concentrations of PAHs compared to those in aquatic sediments and compared to sediment quality guidelines (City of Austin, 2005). The questions remain, however, whether PAHs from parking lot sealers are mobile and whether they might contribute to the high concentrations of PAHs often found in urban waterways. The purpose of this study was to determine concentrations and loads of PAHs in runoff from different types of parking lot surfaces, and to the extent possible, to determine to what degree parking lot sealers are a source of urban PAHs. To investigate the possibility that PAHs from sealed parking lots might be transported to urban creeks, the U.S. Geological Survey (USGS), in cooperation with the City of Austin, sampled runoff and scrapings from four test plots and 13 urban parking lots during August 12-October 6, 2003.

\section{Purpose and Scope}

The purpose of this report is to present sampling methods used for this study and the resulting chemical data. Two experimental approaches were taken: (1) repeated sampling of four test plots (three newly sealed and one unsealed) not exposed to vehicle use and (2) synoptic sampling of parking lots in use with different types of surfaces, both sealed and unsealed. The test plots were in the parking lot at Robert Mueller Municipal Airport, Austin, Tex., which has not been in use since 1999. Immediately before the 
beginning of the study, coal-tar-emulsion sealer was applied to two of the test plots, asphalt-emulsionsealer was applied to one of the test plots, and a control site was not sealed (the entire lot was sealed many years ago, but the sealer appears to have worn off) (table 1). Three times during the 2-month period following application of sealer, distilled deionized (DI) water was applied to the sites using a gentle spray and the washoff was sampled. The sites for the synoptic sampling were in the urban area of Austin (fig. 1). Six of the parking lots had been sealed with coal-tar-emulsion-based sealer, and three parking lots had been sealed with asphalt-emulsion-based sealer; two lots were unsealed asphalt and two lots were unsealed concrete (table 1). Each site was sampled once, using the same approach as that used for the test plots.

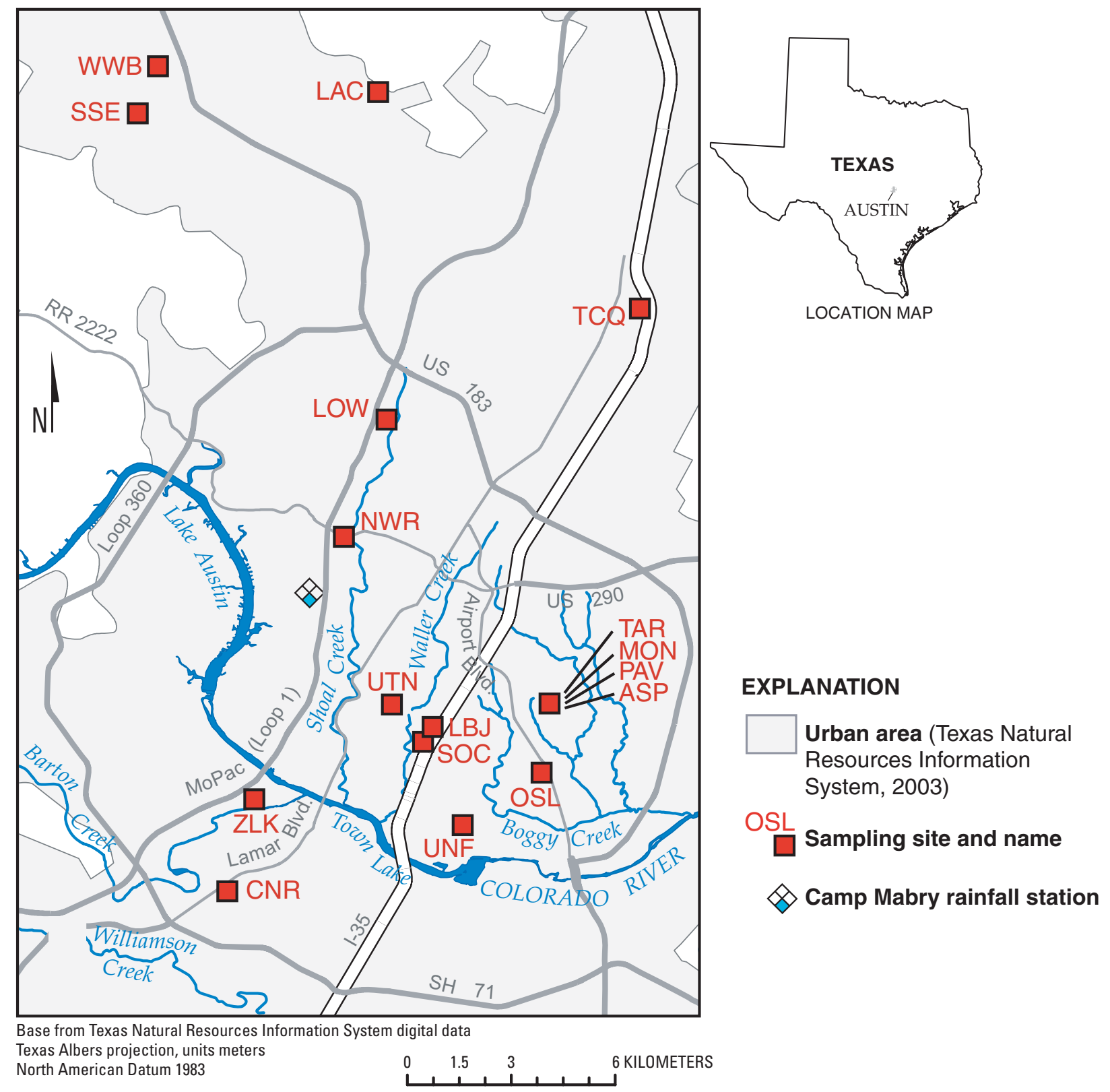

Figure 1. Location of parking lots for sampling of simulated runoff, Austin, Texas, 2003. 
Because the washoff was assumed to contain atmospherically deposited particulates and, in the case of the parking lots in use, particulates from vehicle tires and undercarriages, scrapings of the parking lot surface from most of the sites were analyzed to determine the chemical composition of the surface. Washoff samples were analyzed for a suite of PAHs, major elements, and trace elements in the particulate phase; the scrapings were analyzed for the same suite of PAHs. At a subset of sites, PAHs in the dissolved phase also were analyzed.

\section{Site Selection}

The test plots were in the parking lot of Robert Mueller Municipal Airport (fig. 1). The airport was closed in 1999, and the parking lot has been in minimal use since then. Sometime before 1999, a coal-tar sealer was applied, which appeared to have worn off by the time of this study. Three of the test plots are 11- by 11-meter areas that were sealed during August 5-6, 2003 (table 1). Wheeler Coatings Asphalt, Inc., a commercial pavement-sealing company, on a voluntary basis, agreed to apply a refined coal-tar sealer (Tarconite, less than 34-percent coal tar by weight) to one site (TAR) and an asphalt sealer (Paveshield, less than 35-percent asphalt resin by weight) to one site (PAV). Wheeler personnel prepared the sites for application by blowing off debris and priming oil and grease spots and then applied the two commercial products according to manufacturers' specifications. Application of the coal-tar product also conformed to Federal Specifications R-P 335e and PCTC Guide Specification PCTC01. A retail refined coal-tar sealer (Henry Minuteman-Monsey, 33-percent coal tar by weight), a product available to homeowners for application to residential driveways, was applied to one site (MON) by City of Austin staff following the manufacturer's instructions. No sealer was applied to the control site (ASP). The test plots received virtually no vehicle traffic during the 2-month duration of the sampling.

The parking lots for the synoptic sampling were chosen by City of Austin and USGS personnel to represent a range of surface types and sealer ages (table 1). The type of sealer used and date of sealer application were determined on the basis of information provided by the property owner or manager or from the company that sealed the parking lot. Parking lots of schools, government agencies, municipal facilities, and commercial businesses were chosen to sample various locations in the Austin urban area (fig. 1); all parking lots receive daily vehicle traffic.

\section{Sample-Collection Methods}

Parking lots were sprinkled with simulated rainfall following a minimum of 5 dry days whenever possible, on the basis of rainfall measured at the National Weather Service Austin Camp Mabry station (fig. 2). However, September 2003 was an unusually wet month; in several cases samples were collected following 4 dry days, in one case following 3 dry days (September 30, 2003), and in one case 1 dry day (September 28, 2003). The greatest amount of measured rainfall within the 5 days preceding collection of a washoff sample was 8.6 millimeters (0.34 inch). Rainfall runoff was simulated using 100 liters of DI water sprayed onto a 5- by 10-meter area of the test plots and parking lots. The only exception was the sampling of the test plots on August 12, 2003, when 25 liters of water on a 2.5- by 5-meter area was used on all the test plots except TAR, the test plot with a commercially applied coal-tar sealer (the smaller volume of water was used because it was immediately obvious that insufficient particulates were available for analysis, so samples for analysis of dissolved PAH only were collected). In one instance it rained during the sampling, and actual rainfall runoff was collected instead of the simulated rainfall (TAR test plot, September 26, 2003). To simulate rainfall, water was pumped with a peristaltic pump from 50-liter, highdensity polyethylene (HDPE) carboys through Tygon tubing and a plastic hand-held sprayer (spray rate of about 7 liters per minute) and sprinkled onto the parking lot surface from a height of about 0.75 to 1 meter. Water was blocked at the downslope end of the site either with boards to which weather-stripping had been 
attached (test plots, August 12 and 21, 2003) or with urethane spill berms (all other samples). The collected runoff was pumped into HDPE carboys through Tygon tubing using a second peristaltic pump. Sampling equipment was cleaned between sites with phosphate-free detergent and then rinsed with tap water, DI water, and methanol.

Samples were pre-processed for analysis at the USGS laboratory in Austin. Water recovered during sampling was combined in a 50-liter HDPE carboy equipped with a churn. Samples for measurement of suspended sediment concentration (SSC; Guy, 1969) were collected from the churn to allow quantification of the mass of sediment recovered in each sample. One SSC sample (250-milliliter plastic bottle) was collected at the start of processing. If more than 50 liters of water was recovered, a second SSC sample was collected after the remaining water was added to the churn. For samples collected early in the study, this additional water was added to the churn after sufficient water had been removed by filtration to make room. This approach precludes calculation of a true volume-weighted mean, so for these samples the mean of the two SSC values was used to estimate total sediment recovered (table 5; "Mean of two samples"). An adjustment was made in sample processing beginning with sample PAV collected September 26, 2003, and all samples processed thereafter. If more than 50 liters was recovered for processing, the first SSC sample was collected then the entire remaining volume of the first 50-liter churn was filtered; then the remaining water was added and the second SSC sample was collected. For these samples, the mean SSC is a volume-weighted mean of the two sample fractions (table 5; "Volume-weighted mean"). The volume-

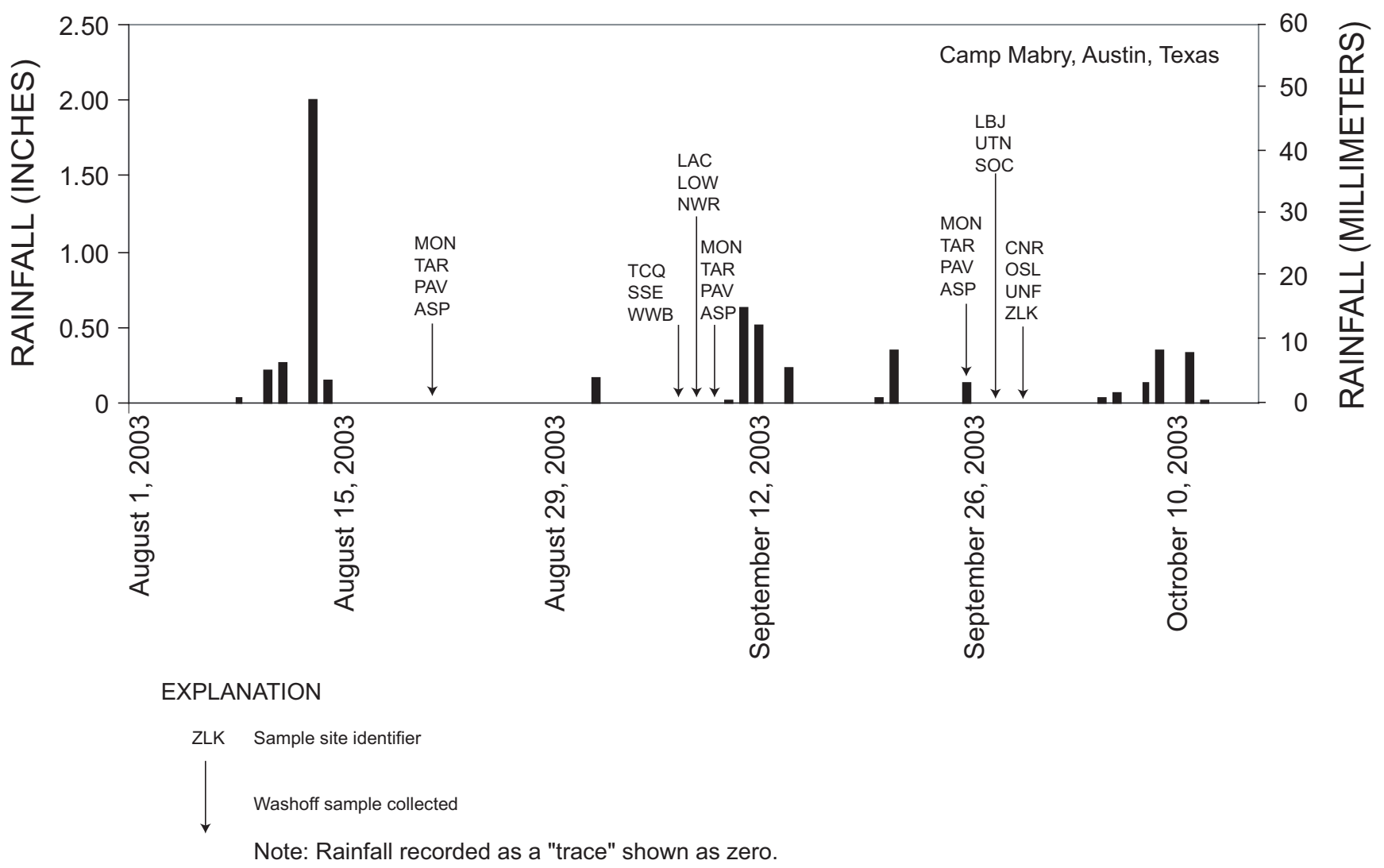

Figure 2. Rainfall for the sampling period as recorded at the National Weather Service Austin Camp Mabry station (National Climatic Data Center, 2006) and dates washoff samples collected. 
weighted-mean concentrations accurately represent the overall mean even if concentrations in the two sample fractions are quite different. Where the mean of two samples was used and the SSCs are relatively similar, the mean of the two samples should reasonably represent the total sample mean.

Samples were filtered through 0.45-micrometer pore size, polytetrafluoroethylene (PTFE) filters following the methods of Mahler and Van Metre (2003). No pre-filter was used. PTFE filters were chosen for use over glass-fiber filters, which must be extracted along with the sediment contained, producing an emulsion that interferes with quantification of the analyte (Mahler and Van Metre, 2003). A stainless steel plate filter holder was used for filtration of particulates for PAH analysis. The filters were massaged inside of locking bags to remove retained particles, and the recovered particles were shipped as chilled slurries in clean glass vials to the USGS National Water Quality Laboratory (NWQL) for analysis. In some cases the filtrate also was shipped, chilled and in clean amber glass bottles, to the NWQL for analysis of dissolved PAH. An acrylic filter holder was used for filtration of particulates for major and trace element analysis. The recovered particulates were freeze-dried and ground before submitting to the NWQL. In all cases, sample-processing equipment was cleaned between samples with phosphate-free detergent, then rinsed with tap water followed by DI water. All equipment used for processing samples for PAH analysis was given a final rinse with methanol.

The test plot and parking lot scrapings were obtained by scraping a small area (less than 0.25 square meter) with a metal paint scraper. The particulates removed were brushed onto a piece of new cardstock and then into a cleaned glass jar. The paint scraper was cleaned between sites in the same manner as the other sampling equipment, and a new brush was used at each site. Scraping samples were not collected from the two unsealed concrete lots because it was assumed that the concrete contains almost no PAHs (PAHs are hydrocarbons and thus are associated with fuels [coal, oil, wood] and combustion of fuels). One sample from an asphalt-emulsion-sealed lot was not analyzed because the sample was corrupted.

\section{Analytical Methods}

\section{PAHs in the Particulate Phase}

Samples were prepared by extracting about 0.5 gram dry weight of sample (mean 0.47 gram, range 0.10 to 1.36 grams) using pressurized liquid extraction at 120 and 200 degrees Celsius with a mixture of water and isopropyl alcohol (50:50 and 20:80 for the two temperatures, respectively). The samples were extracted for 40 minutes at each temperature at a pressure of 13,790 kilopascals. Surrogate compounds were added to the sample prior to extraction to verify method recoveries (table 2). Following extraction, a buffer was added to the extract, and the extract was cleaned using polystyrene divinylbenzene and florisil solid-phase extraction cartridges. The extract was concentrated, solvent-exchanged to ethyl acetate, and diluted to 10 milliliters. An internal standard mixture was added to an aliquot of the extract, and the extract was analyzed by full scan on a Hewlett-Packard 5973 gas chromatography/mass spectrometry (GC/MS) system. Difficult sample matrixes were diluted before the full-scan analysis, and diluted surrogates were estimated in the samples. 
Compound identifications were based on comparison of gas chromatographic peak retention times and mass spectra to those of authentic standard compounds for the target compounds. Response factors were calculated for each compound from a set of calibration standards. For many of the alkyl-substituted PAHs, no authentic standard compounds were available, so the isomers were identified by matching mass spectra in samples with known mass spectra in computerized reference library software (National Institute of Standards and Technology, 2002). The alkyl-substituted PAHs for which standards were not available were quantified using response factors generated from one of the authentic alkyl-homologue compounds in the same alkyl-homologue series. For example, there was no authentic standard for the C4-naphthalene homologue group, so the response factor generated in the calibration standards for 2,6-dimethylnaphthalene was used for its quantitation. The parent PAH response factor was used when no authentic standard was available for a related alkyl-substituted compound within the same homologue series. Quantitation was done following the methods of Olson and others (2004).

For PAHs in the particulate phase, the estimated method reporting level (MRL) is 5 or 10 micrograms per kilogram $(\mu \mathrm{g} / \mathrm{kg})$ for a 25 -gram sample. If less than 25 grams was extracted, the MRL was raised accordingly. In some cases, MRLs were raised because of background interferences. Reporting level for each sample was calculated on the basis of sample mass (table 2), volume of extract, and the MRL. Some concentrations of particle-phase PAHs are flagged as estimated (E) on the basis of one or more qualifiers (table 2). These qualifiers are as follows: $\mathrm{Q}=$ sample or batch of samples for which qualitycontrol (QC) data could not be brought into control guidelines, $\mathrm{I}=$ interference issues from the sample matrix, $\mathrm{n}=$ peak identified and quantified below the reporting level, $\mathrm{v}=$ analyte detected in associated laboratory blank, and $\mathrm{d}=$ dilution. The qualifiers $\mathrm{Q}, \mathrm{I}, \mathrm{n}$, and $\mathrm{v}$ all lead to estimated values_-values that are detections but with lower or unknown precision; values for constituents with highly variable QC data also are shown as estimated. Dilution factors are listed in table 2.

Total PAH ( $\Sigma \mathrm{PAH}$ part $)$ is defined here as the sum of concentrations of 12 parent PAHs (naphthalene, acenaphthylene, acenaphthene, fluorene, phenanthrene, anthracene, fluoranthene, pyrene, benz $[a]$ anthracene, chrysene, benzo[ $[a]$ pyrene, and dibenzo $[a, h]$ anthracene) and 2-methylnaphthalene (Ingersoll and others, 2000) associated with the particulate phase. Raw, unrounded concentrations of individual PAHs were used in the computation of $\Sigma \mathrm{PAH}_{\text {part }}$, and nondetections were assigned a zero value; estimated values were included in the summation at the value reported. Because unrounded values were used to compute $\Sigma \mathrm{PAH}$ part, the sum of rounded PAHs in table 2 might vary slightly in some cases from the reported $\Sigma \mathrm{PAH}_{\text {part }}$ value.

For this report, the C1-128 isomers, methylated naphthalenes (table 2), including 2-methylnaphthalene, were used in the computation of $\Sigma \mathrm{PAH}_{\text {part }}$ to represent 2-methylnaphthylene. This representation could overestimate $\Sigma \mathrm{PAH}_{\text {part }}$ because it might include other monomethylated naphthalene isomers in addition to 2-methylnaphthalene; however, the potential difference is very small. C1-128 isomers, methylated naphthalenes, were detected in only 11 of 40 analyses of particulate PAH (scraping, washoff samples, and duplicates), and the highest percentage of total PAH for which they accounted is 2.1 percent; the next highest percentage is 0.62 percent.

\section{PAHs in the Dissolved Phase}

Samples were analyzed following the method described in Fishman (1993), with the difference that continuous liquid-liquid extraction was substituted for use of the separatory funnel. In brief, 1-liter samples fortified with surrogate compounds were extracted by continuous liquid-liquid extraction for 6 hours under acidic then basic conditions. Internal standards were added and sample extracts concentrated to 1 milliliter. Samples were analyzed by GC/MS in electron impact mode. Sample identifications were made by matching retention times and mass spectra with those of standard compounds. Quantitation 
involved use of internal standards and calibration curves generated by standard compounds of known amounts.

\section{Major and Trace Elements in the Particulate Phase}

For major and trace element analyses, samples were freeze-dried and ground to a powder, and elemental concentrations (with the exception of mercury) were determined on concentrated-acid digests (nitric-hydrofluoric-perchloric acids) by inductively coupled plasma/mass spectrometry (ICP/MS) (Briggs and Meier, 2003). Concentrations of mercury were determined by cold-vapor atomic adsorption spectroscopy (Brown and others, 2003).

\section{Quality-Control Samples}

QC samples consist of environmental QC samples and internal laboratory QC samples (tables 2-4). Results of QC analyses are summarized below. Laboratory precision of the particulate PAH analysis was determined by analysis of two duplicate samples (table 2). Each duplicate was obtained by collecting and filtering a single sample using the same methods used for other samples. The resulting sediment slurry recovered was homogenized and split prior to extraction and analysis. Thus, the duplicates are designed to measure laboratory precision, not the repeatability of the field sample collection. For one of the duplicate samples, $\Sigma \mathrm{PAH}$ part differed by 8 percent (relative percent difference). For the second duplicate (sample with elevated concentrations), $\Sigma \mathrm{PAH}_{\text {part }}$ differed by 54 percent; this duplicate samples was from a site with extremely elevated particulate $\mathrm{PAH}$ concentrations (greater than 4,000,000 $\mu \mathrm{g} / \mathrm{kg} \Sigma \mathrm{PAH}_{\text {part }}$ ).

One equipment blank was analyzed for dissolved PAH (table 3). Three parent PAHs-fluoranthene, phenanthrene, and pyrene-were detected in the blank, but at concentrations more than an order of magnitude less than the MRL. The concentrations in the blank were about one-half the concentrations in the environmental sample with the lowest concentrations (ZLK) and less than 1 percent of concentrations in the environmental sample with the highest concentrations (MON).

Laboratory QC samples for particulate PAH analyses (table 2) consisted of analysis of spiked samples, blanks, and samples of certified reference material (CRM). The surrogate, spike, and CRM values were reported in percent recovered. The method spike was spiked at $20 \mu \mathrm{g} / \mathrm{kg}$. Because a custom method was used, with sparse recovery data, QC criteria are provisional. Representative spike recovery and precision data can be found in Furlong and others (1996). Recovery of the six spiked samples ranged from 6 to 110 percent with a median of 76 percent. For the six laboratory blanks, an analyte was detected in 85 of 336 possible cases, but only 22 detected concentrations were greater than the MRL. The detected concentrations ranged from 0.1 to 3.5 percent of the lowest concentration for that analyte in an environmental sample. For the two analyses of CRM, the recoveries were within the NWQL-established acceptable range for 83 percent of the cases.

Four replicate samples (two each for two sites) and one duplicate sample were analyzed for major and trace elements (table 4). Median relative percent difference between the replicate/duplicate and environmental samples was 4 percent, with a 25 th percentile of 1.4 percent and a 75 th percentile of 13 percent. Precision and accuracy of analyses of CRMs, done internally by the NWQL, were within acceptable limits established by the laboratory (Briggs and Meier, 2003).

\section{PAHs and Major and Trace Elements in Simulated Rainfall Runoff}

Results for PAHs, major and trace elements, and SSCs in the simulated rainfall runoff (washoff) samples are listed in tables 2-5. 


\section{PAHs}

\section{Runoff From Test Plots}

The test plots were washed off three times during the course of 2 months. Concentrations of $\Sigma \mathrm{PAH}_{\text {part }}$ during the three washoff samplings for the four types of surfaces are shown in figure 3. $\Sigma \mathrm{PAH}$ part concentrations in the simulated rainfall runoff for each washoff sampling were greater in the coal-tarsealed test plots than in the asphalt-sealed and unsealed test plots (table 2). Concentrations at three of the test plots, including the control site (ASP), decreased during the course of the three washoff samplings; concentration at one of the coal-tar-sealed test plots increased then decreased. Concentrations of PAHs in particles in parking lot runoff are compared to the probable effect concentration (PEC), a screening-level benchmark. The PEC is the concentration of a contaminant in freshwater aquatic sediment above which adverse effects on sediment-dwelling organisms are expected to occur (MacDonald and others, 2000). The PEC for $\Sigma \mathrm{PAH}_{\text {part }}$ is $22,800 \mu \mathrm{g} / \mathrm{kg}$. Although the particles in parking lot runoff do not in themselves constitute the aquatic sediment for which the PEC was developed, particles in parking lot runoff have the potential to be transported to streams and incorporated into aquatic sediment. Comparison of concentrations in particles associated with parking lot runoff to the PEC allows, for example, consideration of the amount of dilution needed for the PEC to be met. Concentrations of $\Sigma \mathrm{PAH}_{\text {part }}$ exceeded the PEC in all samples except the final sample collected at the control site.

Concentrations of total dissolved PAH $\left(\Sigma \mathrm{PAH}_{\text {diss }}\right.$, defined as the sum of the same PAHs as $\Sigma \mathrm{PAH}_{\text {part }}$ excluding 2-methylnaphthalene) during the three washoff samplings are shown in figure 4. $\Sigma \mathrm{PAH}_{\text {diss }}$ concentrations were about an order of magnitude greater in samples from the coal-tar-sealed test plots than concentrations in samples from the asphalt-sealed test plot, which in turn were about an order of magnitude greater than those from the unsealed test plot (control site ASP). Concentrations decreased over

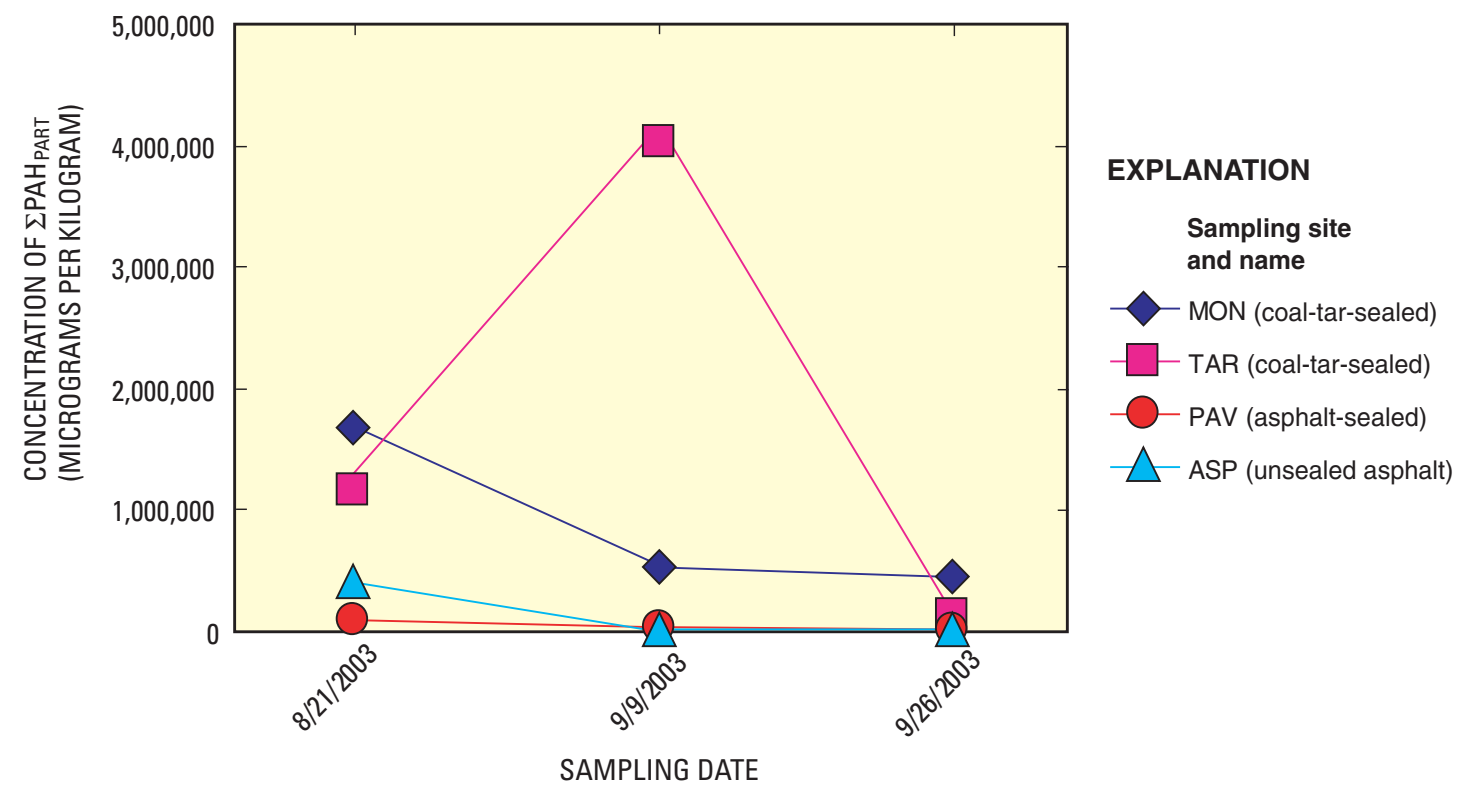

Figure 3. Concentrations of total particulate polycyclic aromatic hydrocarbons $\left(\sum \mathrm{PAH}_{\mathrm{part}}\right)$ in washoff samples from four test plots in Austin, Texas, 2003. 
time at all sealed test plots but generally stayed the same at the control site. Of 17 PAHs analyzed for, nine were detected (table 3). Four PAHs (acenaphthylene, acenaphthene, chrysene, and fluorene) were detected only in runoff from the coal-tar-sealed test plots; anthracene was detected in runoff from all the sealed test plots but not from the control site.

\section{Runoff From Parking Lots in Use}

Concentrations of $\Sigma \mathrm{PAH}_{\text {part }}$ in washoff samples from parking lots in use are shown in figure 5, grouped by type of surface. The mean $\Sigma \mathrm{PAH}_{\text {part }}$ concentrations in runoff from parking lots in use were 3,500,000 (standard deviation [sd] 3,300,000) $\mu \mathrm{g} / \mathrm{kg}$ (coal-tar-sealed lots), 620,000 (sd 320,000) $\mu \mathrm{g} / \mathrm{kg}$ (asphalt-sealed lots), and 54,000 (sd 31,000) $\mathrm{g} / \mathrm{kg}$ (unsealed asphalt and concrete lots combined). Differences between types of surface were compared using the nonparametric Kruskal-Wallis test. The concentration of $\Sigma \mathrm{PAH}_{\text {part }}$ in washoff samples from coal-tar-sealed parking lots was significantly greater than concentrations in samples from asphalt-sealed parking lots ( $\mathrm{p}$-value $=.07$ ) and unsealed parking lots ( $\mathrm{p}$-value $=.01)$, and the concentration in samples from asphalt-sealed parking lots was significantly greater than that from unsealed parking lots $(\mathrm{p}$-value $=.03) . \Sigma \mathrm{PAH}_{\text {part }}$ concentrations in all washoff samples from parking lots exceeded the PEC $(22,800 \mu \mathrm{g} / \mathrm{kg})$ except in one sample from an unsealed asphalt lot (ZLK, table 2).

Concentrations of $\mathrm{SPAH}_{\text {diss }}$ were analyzed at seven of the 13 parking lots in use (fig. 6, table 3). Only one sample from an asphalt-sealed lot was analyzed, so the difference between sealer types could not be compared statistically. The mean $\Sigma \mathrm{PAH}_{\text {diss }}$ concentration in filtered water from parking lots in use was 8.6 (sd 5.4) micrograms per liter $(\mu \mathrm{g} / \mathrm{L})$ for coal-tar-sealed lots; the one sample analyzed from an

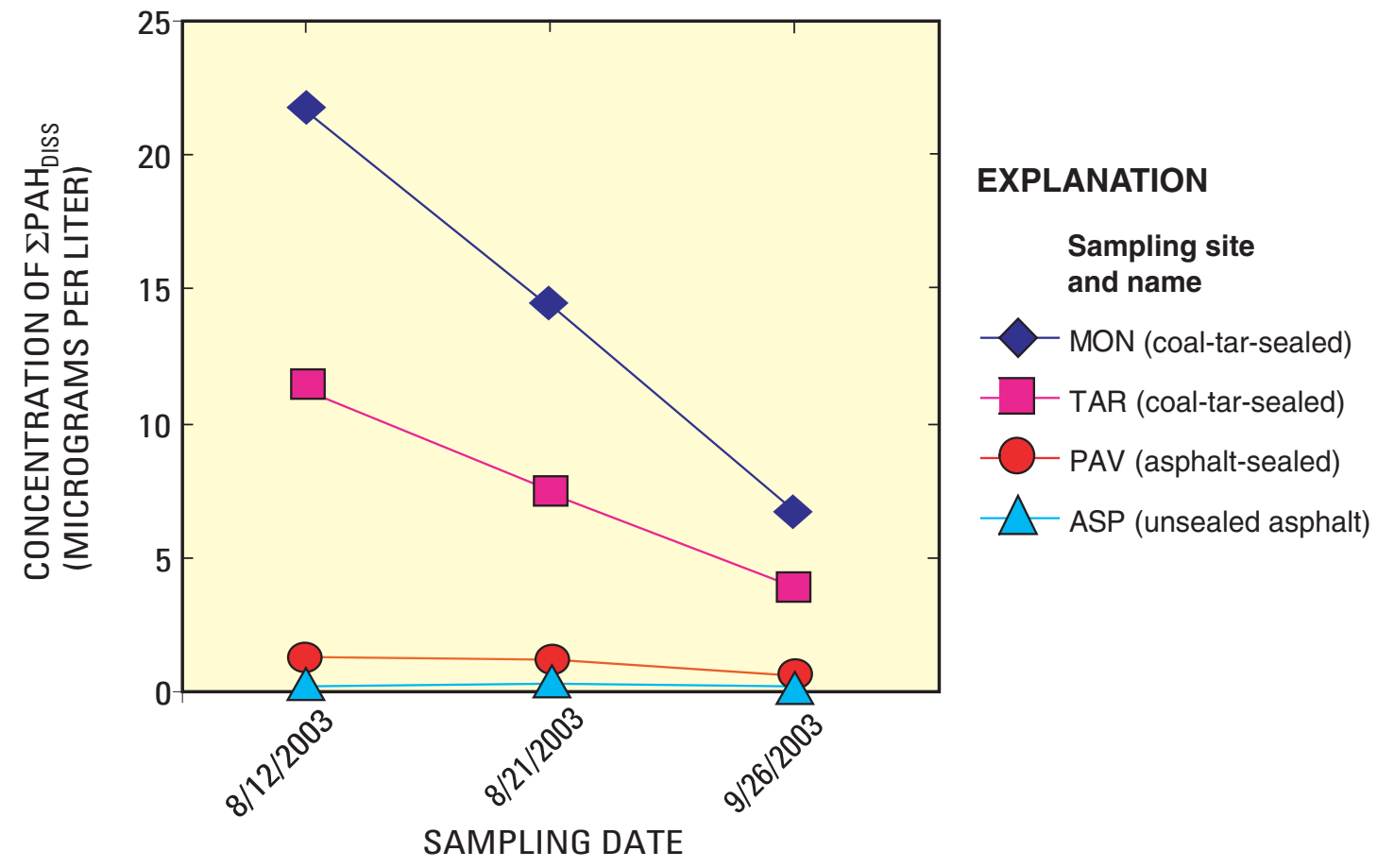

Figure 4. Concentrations of total dissolved polycyclic aromatic hydrocarbons ( $\left.\sum \mathrm{PAH}_{\text {diss }}\right)$ in washoff samples from four test plots in Austin, Texas, 2003. 
asphalt-sealed lot had a concentration of $5.1 \mu \mathrm{g} / \mathrm{L}$, and the one sample analyzed from an unsealed asphalt lot was $0.24 \mu \mathrm{g} / \mathrm{L}$. Similar to PAHs detected in samples from test plots, acenaphthylene, acenaphthene, and fluorene were detected in samples from one or more of the coal-tar-sealed parking lots but were not detected in samples from the asphalt-sealed or unsealed lots (table 3); however, chrysene was detected in the sample from the asphalt-sealed lot. Concentrations of $\Sigma \mathrm{PAH}_{\text {diss }}$ in washoff samples from parking lots in use were similar to those from test plots with the same type of sealer, except the $\Sigma \mathrm{PAH}_{\text {diss }}$ concentration in the washoff sample from the asphalt-sealed parking lot, which was about four times greater than the mean concentration at the asphalt-sealed test plot (fig. 6).

\section{Scrapings}

Scrapings are grouped by type of surface (coal-tar-sealed, asphalt-sealed, and unsealed asphalt) for comparison of $\Sigma \mathrm{PAH}_{\text {part }}$ (fig. 7; table 2). The mean $\Sigma \mathrm{PAH}$ part concentration in scrapings sampled from coaltar-sealed lots was $23,000,000(\mathrm{sd} 25,000,000) \mu \mathrm{g} / \mathrm{kg}$, or 28 times the mean concentration in scrapings from the asphalt-sealed lots $(820,000[\mathrm{sd} 1,000,000] \mu \mathrm{g} / \mathrm{kg})$, which in turn was 59 times the mean concentration in scrapings from the unsealed asphalt lots $(14,000[\mathrm{sd} 9,100] \mu \mathrm{g} / \mathrm{kg})$. The maximum $\Sigma \mathrm{PAH}_{\text {part }}$ concentration detected $(83,000,000 \mu \mathrm{g} / \mathrm{kg}$, or 8.3 percent by weight $)$ was in scrapings of the offthe-shelf coal-tar sealer.

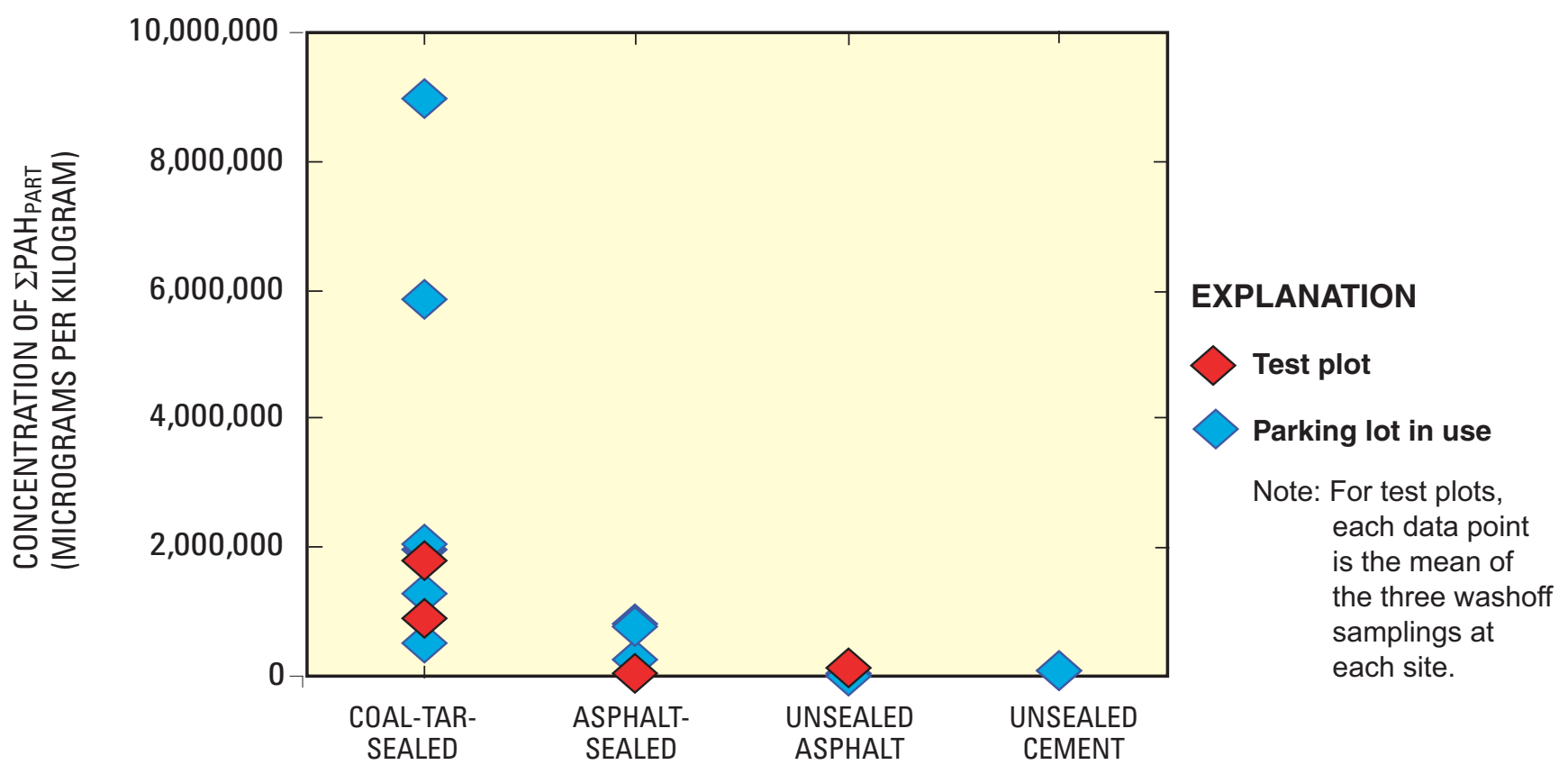

TYPE OF SURFACE

Figure 5. Concentrations of total particulate polycyclic aromatic hydrocarbons $\left(\sum P A H_{p a r t}\right)$ in washoff samples from test plots and parking lots in use, Austin, Texas, 2003. 


\section{Major and Trace Elements (Metals)}

\section{Runoff from Test Plots}

Major elements in particulates washed off the test plots were variable from one washoff sampling to the next, and there was no systematic difference in concentrations between type of surface (table 4). PECs have been established for eight trace elements - arsenic, cadmium, chromium, copper, lead, mercury, nickel, and zinc (MacDonald and others, 2000). During the three washoff samplings, a PEC was exceeded seven times: the PEC for cadmium (4.98 milligrams per kilogram [mg/kg]) was exceeded in one sample from test plot TAR; the PEC for lead $(128 \mathrm{mg} / \mathrm{kg})$ was exceeded in one sample each from test plots ASP, MON, and PAV; and the PEC for zinc $(459 \mathrm{mg} / \mathrm{kg}$ ) was exceeded in the same samples from ASP, MON, and PAV.

\section{Runoff from Parking Lots in Use}

Concentrations of two major elements, calcium and magnesium, were greater in the particulates washed from unsealed parking lots than in those from the sealed parking lots (table 4). Concentrations of other major elements analyzed did not vary on the basis of type of surface. Similar to the results from the test plots, lead and zinc were the trace elements most elevated in particulates washed from parking lots on the basis of comparison to PECS. The PEC for lead was exceeded in samples from some coal-tar-sealed parking lots (TCQ, OSL, LBJ, and UTN) and in samples from both unsealed concrete lots (LAC, LOW), but the PEC was not exceeded in any of the samples from asphalt-sealed or unsealed asphalt parking lots. The PEC for zinc was exceeded in samples from every parking lot except WWB (asphalt-sealed), ZLK (unsealed asphalt), and OSL (coal-tar-sealed).

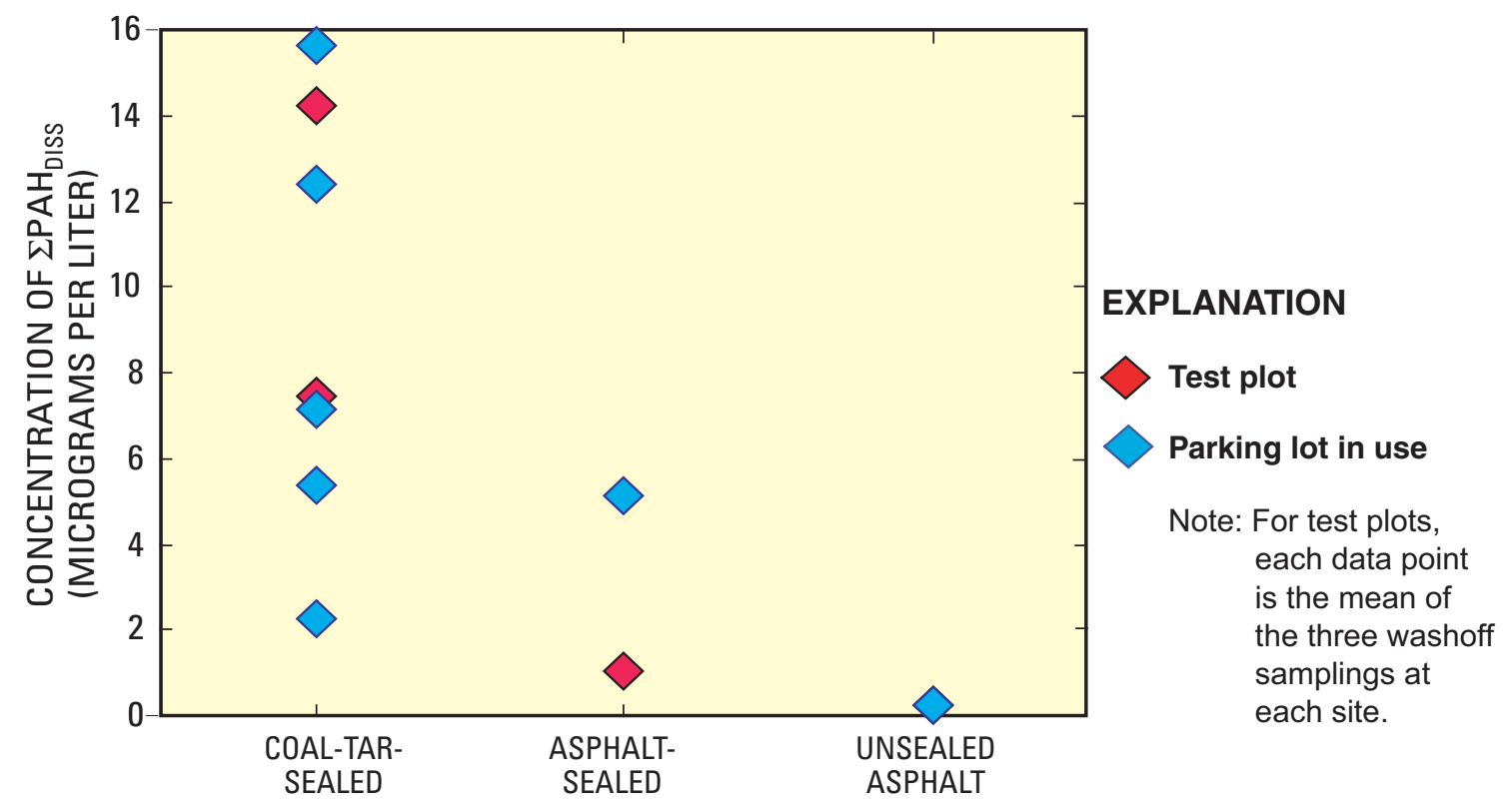

TYPE OF SURFACE

Figure 6. Concentrations of total dissolved polycyclic aromatic hydrocarbons $\left(\sum \mathrm{PAH}_{\mathrm{diss}}\right)$ in washoff samples from test plots and parking lots in use, Austin, Texas, 2003. 


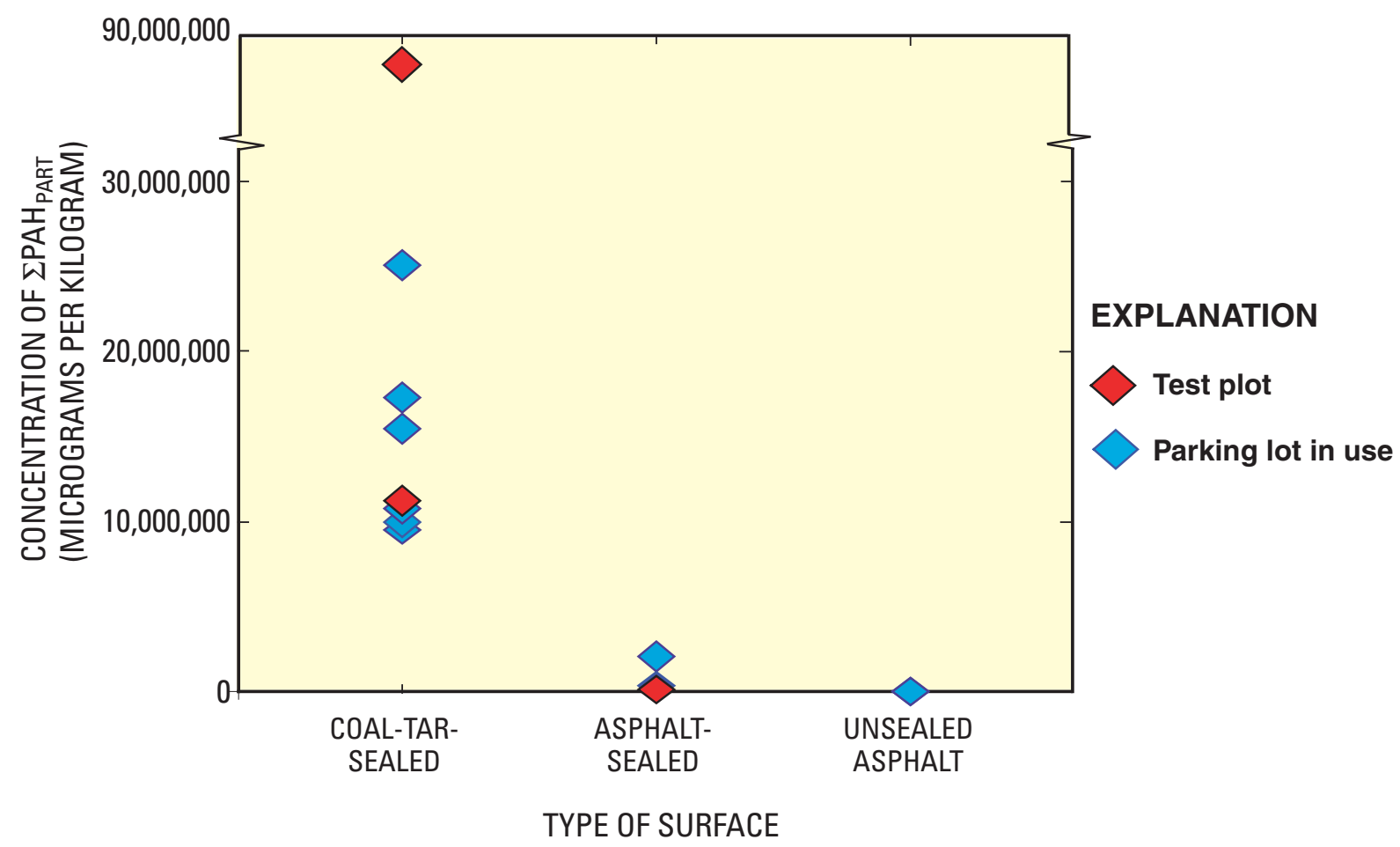

Figure 7. Concentrations of total particulate polycyclic aromatic hydrocarbons ( $\sum \mathrm{PAH}$ part) in scrapings samples from test plot and parking lot surfaces in Austin, Texas, 2003.

\section{References Cited}

Asphalt Sealcoat Manufacturers Association, 2007, Why Sealcoat?, accessed February 15, 2007, at http://www.sealcoatmfg.org/whysealcoat.htm\#When\%20Should\%20sealcoating\%20be\%20done

Björseth, A., and Ramdahl, T., eds., 1985, Handbook of polycyclic aromatic hydrocarbons-Emission sources and recent progress in analytical chemistry, v. 2: New York, Marcel Dekker, 432 p.

Briggs, P.H., and Meier, A.L., 2003, The determination of forty-two elements in geological materials by inductively coupled plasma/mass spectrometry for NAWQA: U.S. Geological Survey Open-File Report 02-223-I, 16 p.

Brown, Z.A., O'Leary, R.M., Hageman, P.L., and Crock, J.G., 2003, Mercury in water, geologic, and plant materials by continuous flow/cold vapor/atomic adsorption spectroscopy: U.S. Geological Survey OpenFile Report 02-223-M, 11 p.

Carolina Asphalt, Inc., 2006, Services, accessed November 22, 2006, at http://www.carolinaasphalt.com/services.html

City of Austin, 2005, PAHs in Austin, Texas, sediments and coal-tar-based pavement sealants polycyclic aromatic hydrocarbons: City of Austin Watershed Protection and Development Review Department, Environmental Resources Management Division, accessed December 14, 2006, at http://www.ci.austin.tx.us/watershed/downloads/coaltar_draft_pah_study.pdf 
Colorado Asphalt Services, Inc., 2006, Frequently asked questions, accessed November 22, 2006, at http://www.coloradoasphalt.com/FAQs.htm

Contractors Register, Inc., 2004, The blue book of building and construction, accessed February 5, 2004, at http://www.thebluebook.com/.

Edwards, N.T., 1983, Polycyclic aromatic hydrocarbons (PAH's) in the terrestrial environment-A review: Journal of Environmental Quality, v. 12, p. 427-441.

Fishman, M.J., 1993, Methods of analysis by the U.S. Geological Survey National Water Quality Laboratory-Determination of inorganic and organic constituents in water and fluvial sediments: U.S. Geological Survey Open-File Report 93-125, 217 p.

Furlong, E.T., Vaught, D.G., Merten, L.M., Foreman, W.T., and Gates, P.M., 1996, Methods of analysis by the U.S. Geological Survey National Water Quality Laboratory-Determination of semivolatile organic compounds in bottom sediment by solvent extraction, gel permeation chromatographic fractionation, and capillary-column chromatography/mass spectrometry: U.S. Geological Survey Open-File Report 95719, $67 \mathrm{p}$.

Guy, H.P., 1969, Laboratory theory and methods for sediment analysis: U.S. Geological Survey Techniques of Water Resources Investigations, book 5, chap. C1, 58 p.

Ingersoll, C.G., MacDonald, D.D., Wang, Ning, Crane, J.L., Field, L.J., Haverland, P.S., Kemble, N.E., Lindskoog, R.A., Severn, Corinne, and Smorong, D.E., 2000, Prediction of sediment toxicity using consensus-based freshwater sediment quality guidelines: U.S. Environmental Protection Agency Report EPA 905/R-00/007, 25 p.

MacDonald, D.D., Ingersoll, C.G., and Berger, T.A., 2000, Development and evaluation of consensusbased quality guidelines for freshwater ecosystems: Archives of Environmental Contamination and Toxicology, v. 39, p. 20-31.

Mahler, B.J., and Van Metre, P.C., 2003, A simplified approach for monitoring hydrophobic organic contaminants associated with suspended sediment-Methodology and applications: Archives of Environmental Contamination and Toxicology, v. 44, no. 4, p. 288-297.

National Climatic Data Center, 2006, Local climatological data-Austin Camp Mabry ANG, TX, accessed December 26, 2006, at http://www7.ncdc.noaa.gov/IPS/LCDPubs?action=getstate\&LCD=hardcode

National Institute of Standards and Technology, 2002, NIST/EPA/NIH Mass Spectral Library with search program, accessed March 24, 2004, at http://www.nist.gov/srd/nist1a.htm

New England Sealcoating, 2003, Sealcoating and striping, accessed February 5, 2004, at http://www.newenglandsealcoating.com/sealcoating.htm

Neyra Industries, 2000, Material safety data sheet for Jennite coal tar emulsion: Cincinnati, Ohio, prepared March 16, 2000.

Olson, M.C., Iverson, J.L., Furlong, E.T., and Schroeder, M.P., 2004, Methods of analysis by the U.S. Geological Survey National Water Quality Laboratory-Determination of polycyclic aromatic hydrocarbon compounds in sediment by gas chromatography/mass spectrometry: U.S. Geological Survey Water-Resources Investigations Report 03-4318, 45 p.

Potts, P.J., Tindle, A.G., and Webb, P.C., 1992, Geochemical reference material compositions-Rocks, minerals, sediments, soils, carbonates, refractories, and ores used in research and industry: Baca Raton, Fla., CRC press, 313 p.

Riegler Blacktop, Inc., Information on commercial sealcoat products and application, accessed December 5, 2006, at http://rieglerblacktop.com/commercialseal.html

SealMaster, 2002, Material safety data sheet for SealMaster coal tar pavement sealer product no. S1000: Sandusky, Ohio, prepared February 21, 2002. 
Sims, R.C., and Overcash, M.R., 1983, Fate of polynuclear aromatic compounds (PNAs) in soil-plant systems: New York, Springer-Verlag New York Inc., Residue Reviews, v. 88, p. 1-67.

STAR, Inc., 1996, Material safety data sheet for Star Seal asphalt pavement sealer: Columbus, Ohio, prepared July 18, 1996.

Takada, Hideshige, Onda, Tomoko, and Ogura, Norio, 1990, Determination of polycyclic aromatic hydrocarbons in urban street dusts and their source materials by capillary gas chromatography: Environmental Science and Technology, v. 24, no. 8, p. 1,179-1,186.

Texas Natural Resources Information System, 2003, Data catalog: accessed December 29, 2003, at http://www.tnris.state.tx.us/DigitalData/data_cat.htm

U.S. Department of Health and Human Services, 2002, Report on carcinogens (10th ed.): Research Triangle Park, N.C., National Toxicology Program, Public Health Service.

Van Metre, P.C., Mahler, B.J., and Furlong, E.T., 2000, Urban sprawl leaves its PAH signature: Environmental Science and Technology, v. 34, no. 19, p. 4,064-4,070. 